\title{
Habitat segregation, competition and selective deforestation: effects on the conservation status of two similar Petaurus gliders
}

\author{
Coral Rowston* and Carla P. Catterall
}

Faculty of Environmental Sciences, Griffith University, Nathan QId, 4 I I I, Australia

*Present address: Environmental Protection Agency, PO Box 31 30, Rockhampton Shopping Fair, QId, 470 I. Email: Coral.Rowston@epa.qld.gov.au

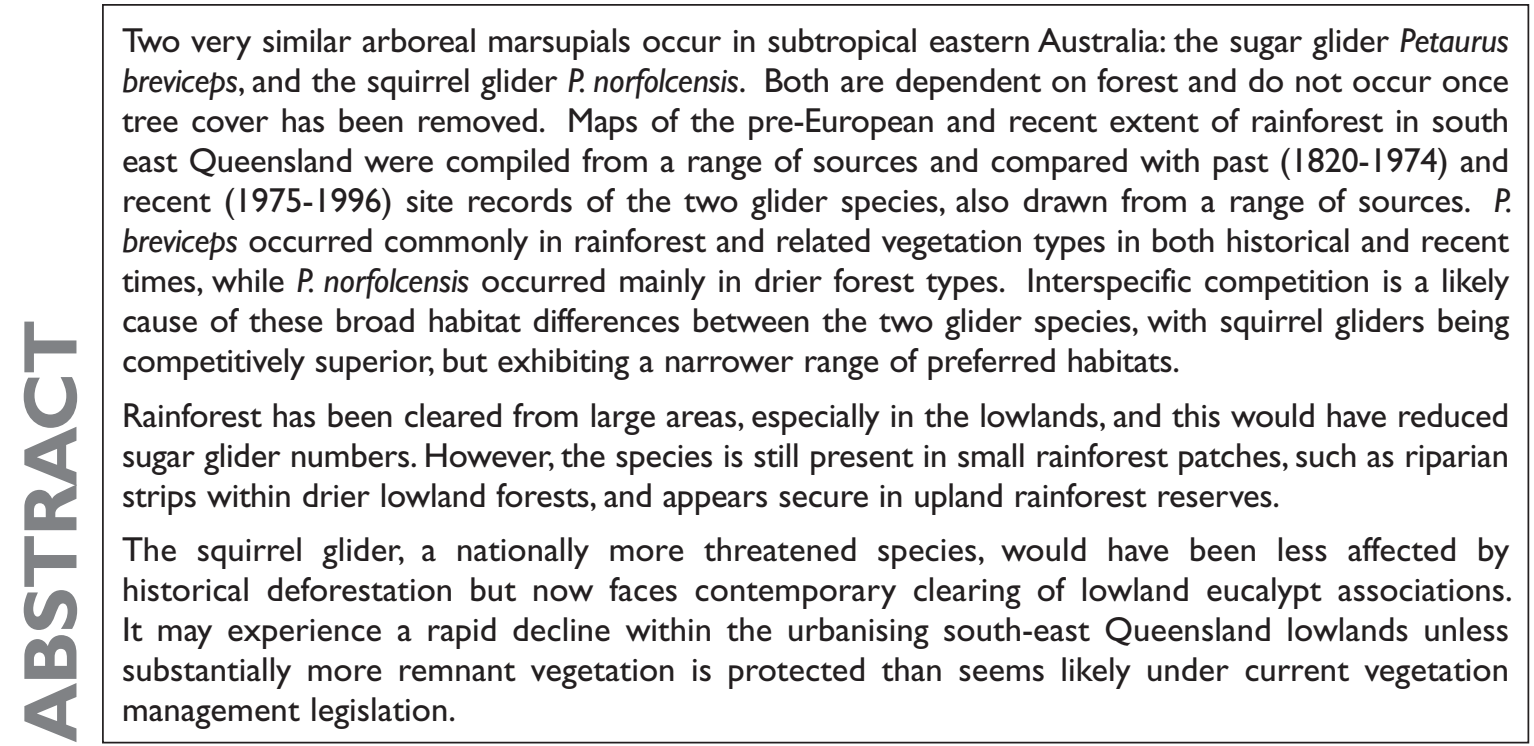

Key words: sugar glider, Petaurus breviceps, squirrel glider, Petaurus norfolcensis, habitat selection, rainforest, eucalypt forest, Brisbane.

\section{Introduction}

Four species of Petaurus gliding possums are currently recognised in Australia, the largest being the yellowbellied glider $P$. australis, followed by the mahogany glider $P$. gracilis, the squirrel glider $P$. norfolcensis and the sugar glider P. breviceps (Strahan 1995). All four species have a diet consisting of insects, pollen and exudates (Smith and Lee 1984; Van Dyck 1993; Russell 1995; Rowston 1998b). All species are arboreal and their typical movement pattern is gliding between trees. Gliding possum populations are restricted to forest areas and all are vulnerable to local and regional declines in situations where there has been large-scale deforestation.

Past deforestation has resulted in the mahogany glider being considered nationally endangered (this species is restricted to coastal lowland woodland in northern Queensland), the northern subspecies of the yellow-bellied glider is considered vulnerable, and the squirrel glider is considered endangered at the southern extent and vulnerable in the centre of its distribution (Environment Protection and Biodiversity Conservation Act 1999; New South Wales Threatened Species Conservation Act 1995; Victorian Flora and Fauna Guarantee Act 1988; Queensland Nature Conservation (Wildlife) Regulations 1984). The squirrel glider occurs from Victoria to northern Queensland, but is apparently absent from Cape York Peninsula. The sugar glider has a broader distribution along both the eastern and northern coasts of Australia, extending into New Guinea and the surrounding islands (Smith 1973) and is not currently considered to be of sufficient conservation concern to be listed in the schedules of the State or Commonwealth conservation legislation.

Sugar gliders occur in a range of forest complexes from drier coastal eucalypt forests and woodlands, through to moister rainforest habitats (Winter 1984). They have been described as common and not dependent on any particular habitat type, although the presence of Acacia species may be an important population limiting factor (Smith 1980, 1982, 1993; Suckling 1984). By contrast, squirrel gliders have been reported only from dry eucalypt forests and woodlands (Menkhorst et al. 1988; Bennett et al. 1991; Quin 1995; Traill and Lill 1997; Rowston et al. 2002).

In spite of the difference in their geographical extent and conservation status, the sugar and squirrel glider are remarkably similar in appearance (Smith 1973; Alexander 1981) and have interbred in captivity (Fleay 1947). They both require tree hollows for nesting (Traill and Lill 1997; Rowston 1998a), live in family groups of between 2 and 10, 
and have a diet consisting of exudates, insects and pollen (Smith 1982; Menkhorst and Collier 1987; Rowston 1998b). The sugar glider is smaller than the squirrel glider (95-160 g and 200-260 g respectively; Suckling 1995), although this difference is reduced in the northern part of their range, where squirrel gliders are smaller (Alexander 1981). The two species are also sympatric throughout large parts of their distribution in eastern Australia (Quin 1993), providing a high potential for interspecific competition and/or region-specific niche shifts.

The present study investigates the extent to which these two species are ecologically segregated by local habitat type within the south-east Queensland region in subtropical eastern Australia, around the centre of the squirrel glider's geographical range. We use data on the site-specific occurrence of the species from two time periods (historical and recent) to assess habitat use patterns, consider the evidence for competitive interactions between the species, and assess the effects of past and recent deforestation patterns on their distributions and ecological relationships.

\section{Study area and methods}

\section{Study area}

The study area is the SEQ2001 region of south-east Queensland (Fig. 1; Catterall et al. 1997), covering an area of about $22500 \mathrm{~km}^{2}$, ranging from the Queensland/ New South Wales border (28 ${ }^{\circ} 20^{\prime}$ S) north to Cooloola

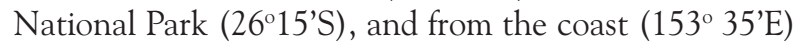
west to the great Dividing Range ( $\left.151^{\circ} 51^{\prime} \mathrm{E}\right)$. The study region occupies about one-third of the broader Southeast Queensland biogeographical region (Young and Dillewaard 1999).

The region's topography is complex, with mountain peaks above $1000 \mathrm{~m}$, although $86 \%$ of land is below $400 \mathrm{~m}$ (Catterall et al. 1997). The climate is primarily subtropical, with annual rainfall of $800-1500 \mathrm{~mm}$ per year, summer rainfall being about twice winter rainfall (Young and Dillewaard 1999). Variation in topography and local climate are associated with a complex vegetation mosaic that includes drier eucalypt forests and woodlands, rainforest, moist eucalypt forest with rainforest understorey, heathland and melaleuca wetlands. The region is one of the richest parts of Australia for flora and fauna (Young and Dillewaard 1999). Prior to European settlement, most of the study region supported forest or woodland but $66 \%$ had been cleared by about 1990, with lowland forest types most affected (Catterall et al. 1997; Young and Dillewaard 1999).

\section{Past and recent distribution of rainforest}

A number of different vegetation maps have been compiled for the study region, at different spatial scales, and these maps provide some information on the area covered by vegetation at different time periods before and during the period of European settlement. The main sources used here are: pre-European (c. 1820) and c. 1950 rainforest maps by Webb (1956); a rainforest map by Young and McDonald (1987); a 1989 remnant bushland map (Kingston et al. 1991); and overlays of remnant bushland with previously mapped vegetation types in Catterall and Kingston (1993).
The term "bushland" is used here to denote all forms of remnant indigenous woody vegetation cover.

For this study, the information from these sources was integrated within two 1:750 000 maps showing "past" (preEuropean) and "recent" (c. 1990) rainforest distributions. Other forest types were not mapped, although it is assumed on the basis of extensive ancillary information that all records of Petaurus gliders correspond with the presence of some form of forest cover. A glider record outside a rainforest is thus presumed to correspond with drier eucalypt or melaleuca forests or woodlands. The map sources and their specific interpretation and use are described in detail in Rowston (1998b). "Rainforest" here includes both closed vine forest and floristically related types such as semi-evergreen vine thickets and "moist eucalypt" (also termed "wet sclerophyll") forests in which there are eucalypt emergents above a rainforest understorey.

The pre-European rainforest included areas of past rainforest as mapped by Webb (1956). This map was based on stereoscopic air photos from 1931 to 1954 , together with ground truthing, and was presented at 1: 400000 (but compiled at 1:126 720). Webb (1956) also delineated areas of rainforest that had been cleared between European settlement (c. 1820) and 1954 based on historical information together with extrapolation (areas with appropriate soil type adjacent to standing rainforest were considered to have supported rainforest prior to European settlement). Areas smaller than about 16 ha and narrow riparian strips were not mapped. For the present study, some smaller areas of rainforest that occurred along the Brisbane River at the time of European settlement (as described by early explorers cited in Young 1990) were also added to the map of past distribution of rainforest. In 2001, the Queensland Herbarium (Queensland Environmental Protection Agency) produced 1:100 000 maps of presumed preEuropean vegetation types, using the mapping technique of inferring past vegetation type from current trees in an area (presumed to be remnants of the original vegetation). However, a comparison of these maps with those of Webb (1956), as well as information in Young (1990) and other historical accounts indicates that in these maps some areas of known past rainforest cover are shown as eucalypt forest. Such interpretations are likely when clearing of rainforest that was originally present in a mosaic with drier forests was followed by frequent burning. Hence for this study we used the more historically-based sources.

The map of "recent" rainforest incorporated all areas designated as rainforest by Young and McDonald (1987) and as remnant rainforest in 1989 by Catterall and Kingston (1993). Areas that were indicated as both rainforest in 1931-1954 by Webb (1956) and standing remnant bushland in 1989 by Kingston et al. (1991) were also mapped as recent rainforest. For the areas of bushland not mapped by Kingston et al. (1991), recent rainforest was simply mapped according to the 1931-1954 rainforest distribution by Webb (1956). Although the latter may be inaccurate for the 1990s, lack of fauna data for this area (the extreme western and southern parts of the study area) prevented this from being a problem for the present study. In addition, areas that were indicated by Webb (1956) as rainforest cleared between 1820 and 
1950, but as standing bushland in Kingston et al. (1991), were also considered to be "recent rainforest" but were differentiated on the map. These areas may be regrowth since 1950 and/or may have changed from rainforest to a more eucalypt-dominated vegetation type through land management practices (such as logging or burning).

\section{Past and recent records of sugar gliders and squirrel gliders}

Records of sugar glider and squirrel glider locations were obtained from the Queensland Museum, whose database of museum specimens (mostly collected opportunistically over a number of years) included the species, collection date, locality, and the latitude and longitude (to the nearest minute) of the collection locality. "Past" glider records were defined as museum records of sugar or squirrel gliders from within the study area prior to 1974 . "Recent" glider records comprised museum records of sugar and squirrel glider localities from within the study area between 1974 and 1990 together with other records from wildlife care groups (community groups that look after sick and injured native animals) and records from Rowston (1998b).

Both the past and recent records of the two glider species were concentrated around the Brisbane area, where the human population density is greatest, with scattered records from the remainder of the region. This reflects a collector-bias associated with the source of museum specimens, rather than any underlying spatial variation in glider densities. In spite of this bias, the data can be used to compare the habitat use of the two species, since there

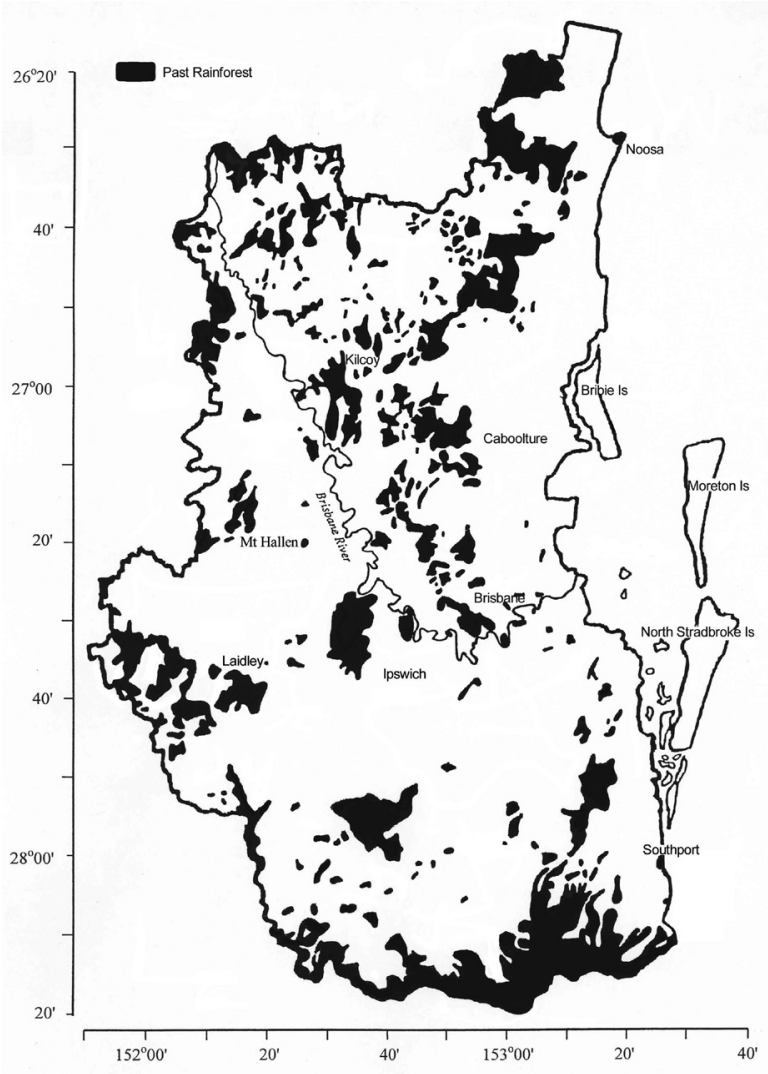

is no reason to expect that either species, if present at a site, would be more likely to be collected than the other.

The past and recent glider records were plotted on 1:100 000 reproductions of the past and recent rainforest maps respectively. Each glider record was judged as being either "in" or "out" of known rainforest for the corresponding time-period (past or recent). Records "out" of rainforest were considered to be in eucalypt forest (rather than cleared land) because of the known forest-dependence of both species. Some of these may be from small rainforest strips or patches not mappable at the scale used (typically less than 10-20 ha area or 100-200 m width). The "recent" (1990) maps of rainforest should correspond fairly accurately with the 1974-1990 time period of glider records because little clearing of rainforest occurred during that time. The "past" (1820) maps, when matched with glider records up to 1974 , may have resulted in some "out" records from the mid-1900s being scored as "in" if they occurred in former rainforest or moist eucalypt forest areas that were converted during the 1900 s to eucalypt forest by management practices such as burning. However, this bias would be consistent across both glider species.

Topographic maps (also 1:100 000) were used to allocate each glider record to one of three elevation categories (based on information in Rowston et al. 2002): less than $80 \mathrm{~m}, 80-300 \mathrm{~m}$ and more than $300 \mathrm{~m}$. Selected aspects of the strength of association between the presence of glider species, the occurrence of mapped rainforest, the elevation, and the two time periods was tested with a series of contingency tables, and the chi-squared statistic.

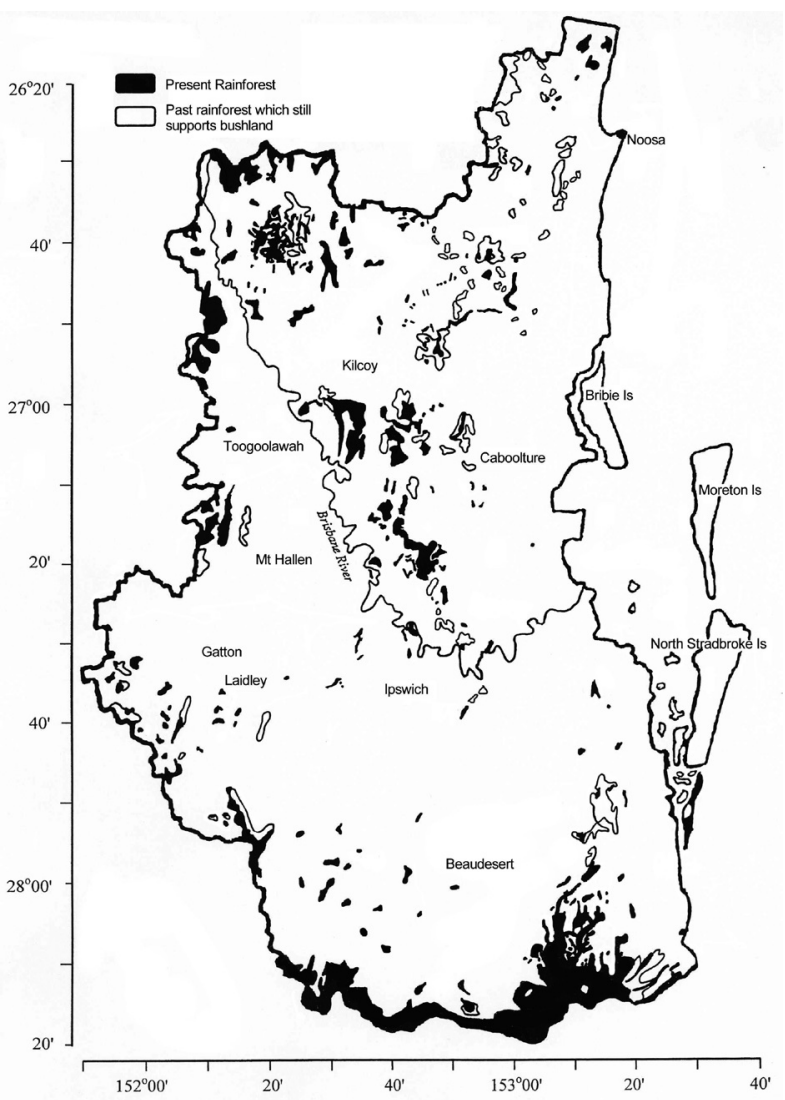

Figure I. Past (around 1820) and recent (around 1990) distributions of rainforest in the study region. See text for details. 
Table I. Frequencies of sugar and squirrel glider records in and out of mapped rainforest.

\begin{tabular}{|c|c|c|c|c|c|}
\hline \multirow[b]{2}{*}{ Glider species: } & \multicolumn{2}{|c|}{ Habitat type: } & \multirow[b]{2}{*}{ Total } & \multirow{2}{*}{$\%$} & \multirow{2}{*}{$\begin{array}{c}\text { Comparison } \\
\text { marker }\end{array}$} \\
\hline & Rain-forest & Other forest & & & \\
\hline \multicolumn{6}{|c|}{ Past records with past forest: } \\
\hline Sugar & 10 & 3 & 13 & $77 \%$ & $\mathrm{a}$ \\
\hline Squirrel & 7 & 34 & 41 & $17 \%$ & $b$ \\
\hline \multicolumn{6}{|c|}{ Recent records with recent forest: } \\
\hline Sugar & 9 & 5 & 14 & $64 \%$ & C \\
\hline Squirrel & 4 & 51 & 55 & $7 \%$ & d \\
\hline \multicolumn{6}{|l|}{ All records: } \\
\hline Sugar & 19 & 8 & 27 & $70 \%$ & e \\
\hline Squirrel & 10 & 87 & 97 & $10 \%$ & f \\
\hline \multicolumn{6}{|c|}{$\begin{array}{l}\text { Paired comparisons (using } 2 \times 2 \text { contingency tables, with } 2 \text { tests): } \\
\text { a vs b, c vs } d \text {, and e vs f: } P<0.000 \text { I, } \\
\text { a vs c: } P=0.47\end{array}$} \\
\hline
\end{tabular}

\section{Results}

Prior to European settlement, rainforest was patchily distributed throughout the south-east Queensland region (Fig. 1). The remaining area was covered in other vegetation types, mostly drier eucalypt forest associations. By 1974, the total rainforest area had decreased substantially (Fig. 1) and the balance of the land area supported a mosaic of drier vegetation types and cleared or developed land (including pasture, cropland, plantation and urban).

In both past and recent times, rainforest at higher elevations has often been arranged in large blocks, whereas some lowland rainforest comprised narrow riparian strips along waterways within larger areas of eucalypt forest or other sclerophyll forest types. Large blocks of rainforest occurred in the lowlands prior to European settlement, but now the remaining large rainforest tracts are confined to the mountain ranges due to the disproportionate clearing of lowland rainforests.

The two glider species differ substantially and significantly from one another in their association with both past and recent rainforest vegetation (Table 1 ). Sugar gliders were recorded mainly in association with rainforest and related habitats, with $77 \%$ of past and $64 \%$ of recent records coinciding with the mapped rainforest areas, while only $17 \%$ and $7 \%$ of squirrel glider records showed this association (Table 1).

Both species show a declining degree of coincidence with rainforest when past and recent times are compared (Table 1); sugar gliders declined from $77 \%$ to $64 \%$ coincidence, and squirrel gliders from $17 \%$ to $7 \%$, although these differences are not statistically significant and may be due to the mapping biases described earlier. In recent times (where such biases would be least) the squirrel glider has shown a stronger separation from rainforest ( $93 \%$ of records not coinciding with mapped rainforest) than the sugar glider's association with rainforest (64\%). The cut-off date differentiating the past and recent distribution of sugar and squirrel gliders was chosen at 1974 because the rate of clearing of rainforest within the region was very low between 1974 and 1989 (0.8\% in the coastal areas of south east Queensland; Catterall and Kingston 1993), in contrast with the large losses of rainforest in the region since European settlement (c. 1820; see Fig 1).

Most records of both species were from the lowlands $(<80 \mathrm{~m}$, Table 2$)$, reflecting in part the distribution of the people who collected the specimens (human-occupied parts of the landscape are mostly at lower elevations). Squirrel gliders were most strongly associated with low elevations ( $85 \%$ of records were below $80 \mathrm{~m}$ during both time periods, compared with $71 \%$ and $77 \%$ for sugar gliders), although the difference between the species for records $<80 \mathrm{~m}$ compared with $>80 \mathrm{~m}$ was not statistically significant. Sites above $300 \mathrm{~m}$ accounted for only $2 \%$ of squirrel glider records at both times, compared with 23 $29 \%$ of sugar glider records (data in Table 2), and this comparison is statistically significant for both time periods (2; $P<0.05$ for past, $P<0.001$ for recent records). In general, higher-elevation records of both species were more likely to be scored as "rainforest" than lowerelevation records, however there were no detectable changes in this difference over time.

\section{Discussion}

\section{Habitat segregation and competition}

The high level of morphological and behavioural similarity between sugar and squirrel gliders, and their coincident geographical ranges in south-east Queensland means that there is a high probability that these species could be direct competitors in this region. Interspecific competition may result in either a change in resource use (niche segregation) or an altered species' abundance due to a change in natality, mortality, immigration or emigration (Connell 1983). 
Table 2. The frequency of sugar and squirrel glider records at different elevations, and their proportionate occurrence in mapped rainforest.

\begin{tabular}{|c|c|c|c|c|c|c|c|}
\hline \multirow[b]{2}{*}{ Glider species: } & \multicolumn{4}{|c|}{ Records in elevation classes: } & \multirow{2}{*}{$\begin{array}{c}\% \text { all records } \\
\text { that were }<80 \mathrm{~m}\end{array}$} & \multicolumn{2}{|c|}{$\begin{array}{c}\% \text { of records that were in } \\
\text { rainforest at: }\end{array}$} \\
\hline & $<80 \mathrm{~m}$ & $80-300 \mathrm{~m}$ & $>300 \mathrm{~m}$ & Total & & $<80 \mathrm{~m}$ & $>80 \mathrm{~m}$ \\
\hline \multicolumn{8}{|l|}{ Past records: } \\
\hline Sugar & 10 & 0 & 3 & 13 & $77 \%$ & $70 \%$ & $100 \%$ \\
\hline Squirrel & 35 & 5 & I & 41 & $85 \%$ & $14 \%$ & $33 \%$ \\
\hline \multicolumn{8}{|l|}{ Recent records: } \\
\hline Sugar & 10 & 0 & 4 & 14 & $71 \%$ & $50 \%$ & $75 \%$ \\
\hline Squirrel & 47 & 7 & | & 55 & $85 \%$ & $6 \%$ & $13 \%$ \\
\hline
\end{tabular}

Across their entire geographical distribution, sugar gliders occur in rainforests, moist eucalypt, and dry eucalypt forests and woodlands (Suckling 1984; Winter 1984; Bennett et al. 1991). Despite the diversity of habitats used by sugar gliders, several authors have suggested that their optimum habitat is tall open (eucalypt) forest (Tyndale-Biscoe and Calaby 1975) or (eucalypt) forest and woodland (Braithwaite 1983; Winter 1984; Suckling 1984). In support of this, in north Queensland (outside the squirrel glider's geographic distribution) where sugar gliders are known from rainforest habitats, they are still more common in adjacent eucalypt forest areas (Winter 1984). However, the results presented here indicate that in south-east Queensland, sugar gliders occur mainly in areas that support rainforest vegetation. These areas include small patches or riparian strips within larger tracts of open sclerophyll forest or woodland, as well as extensive rainforest tracts, and ecotones between rainforest tracts and sclerophyll forest. Many sugar glider records that were "outside" rainforest may in fact be from small rainforest patches that were not visible at the map scale used.

In contrast, squirrel gliders are known only from eucalypt forests and woodlands throughout their distribution (Menkhorst et al. 1988; Bennett et al. 1991). In south-east Queensland, a field trapping study has shown that squirrel gliders are common in lowland eucalypt associations but are absent from riparian rainforest and "wet sclerophyll" sites whose vegetation consists of emergent eucalypts over an understorey with many rainforest shrubs (Rowston et al. 2002). The latter sites did not support compensatory numbers of sugar gliders (Rowston 1998b), so squirrel gliders would not have avoided these sites because they were occupied by sugar gliders. Furthermore, other ecological research into these species in the subtropics has shown that the squirrel glider is behaviourally dominant over the sugar glider (Quin 1995).

In southern Australia, near the range limit of the squirrel glider, there is also either differential use of the varying eucalypt forest associations or segregation at a fine spatial scale between sugar and squirrel gliders (Menkhorst et al. 1988; Bennett et al. 1991). In subtropical New South Wales, sugar and squirrel gliders co-existing at one eucalypt forest study site used tree and shrub associations in different proportions (Quin 1993). Also, in New South Wales, Davey (1984) found that both sugar and squirrel gliders generally used different floristic and structural habitat types, that sugar gliders used a broader habitat range including the riparian and wet sclerophyll vegetation types, and where they did occur together in the drier eucalypt forest and woodlands, they partitioned spatially with squirrel gliders using the upper canopy and sugar gliders using the lower canopy.

There is therefore a general lack of co-existence of sugar and squirrel gliders on the local scale in places where they are sympatric, but South-east Queensland is the only region from which such distinct broad habitat differences have been reported. Sugar gliders are relative generalists that can use a wide variety of different forest and woodland types including both rainforest and eucalypt forest. However, in south-east Queensland they exhibit a narrower choice of habitats than in many other parts of their geographic distribution and those parts of the habitat spectrum that they are avoiding are the drier eucalypt associations preferred by the ecologically similar and behaviourally dominant squirrel glider. Furthermore, it seems unlikely that sugar gliders have an active preference for dense, rainforest habitat. When a species exhibits a wider choice of habitats in the absence of competitors than it does where competing congeners occur, interspecific competition is likely to be an underlying cause (Chappell 1978; Ziv et al. 1993). In south-east Queensland, squirrel gliders show high population densities compared with other regions (Rowston 1998b), increasing the likelihood of interspecific interactions that could exclude sugar gliders. The sugar gliders in this region may prefer situations where rainforest occurs near to, or together with, eucalypts; this can only be clarified through further field studies.

\section{Implications for conservation}

Both the sugar and squirrel gliders are forest-dependent species whose regional population density and distribution will decline in proportion to the amount of suitable forest habitat in the landscape that has been cleared. While the sugar glider has not yet become sufficiently depleted to be considered threatened in any part of its distribution, the squirrel glider has undergone 
serious declines in the southern part of its range (Menkhorst et al. 1988). Furthermore, the squirrel glider is an "icon" species in the south-east Queensland region, whose image is currently in use as a symbol to promote regional awareness and pride ("The Great Southeast" campaign involving television, newspaper and business advertisements since 1992).

Between about 1850 and 1996, 66\% of the formerly continuous bushland cover in south-east Queensland was removed and converted to pasture, urban development, or other forms of land cover unsuitable for Petaurus gliders. This deforestation has targeted lowland areas in particular, with $83 \%$ of vegetation cleared below $60 \mathrm{~m}$, compared with $79 \%$ at $60-160 \mathrm{~m}$ and $45 \%$ above $160 \mathrm{~m}$ (Catterall et al. 1997). In terms of vegetation type, the first wave of clearing (up to the early twentieth century) largely targeted rainforest areas (Webb 1956), with the result that lowland rainforest patches are small, with almost none above a few tens of hectares (Young and McDonald 1987; Catterall and Kingston 1993). However, rainforest is still widely distributed as remnant trees, very small patches or strips typically associated with gullies or fire-free areas within larger patches of eucalypt forest. In recent years, clearing of the eucalypt associations has continued. For example, between 1974 and 1989, 50\% of eucalypt forest cover was cleared from the coastal section of the study region (Catterall and Kingston 1993).

In spite of this clearing, the results of this study show that both glider species remain widely distributed throughout south-east Queensland (although total population numbers have undoubtedly declined). Local high-density populations of the squirrel glider can still be found in many remnant lowland eucalypt forest patches above 20 ha within the urbanising greater Brisbane region (Rowston et al 2002), although their future may be precarious due to ongoing high deforestation rates (Catterall et al. 1997, Rowston et al 2002). Squirrel gliders in south-east Queensland rarely occur above $300 \mathrm{~m}$, and in the lowlands they are most abundant in ironbark - spotted gum forests of sub-coastal hills (primarily Corymbia citriodora / Eucalyptus crebra / E. siderophloia, but including other closely related or co-dominant species), and in heathy woodlands dominated by scribbly gum ( $E$. racemosa), and especially where the density of old hollowbearing trees is high (Rowston et al. 2002).

It might be expected that the distribution of sugar gliders would have retracted in recent times to higher elevations where the cover of rainforest and moist eucalypt forests remains extensive. However, this has not occurred. Rather, the sugar gliders appear to have persisted in association with the remaining dispersed and fragmented rainforest elements. This is consistent with the generalised habitat use patterns and ecological flexibility discussed above. It is also possible that the squirrel glider has expanded in local lowland areas at the expense of the sugar glider where partial clearing and the use of fire have been used to convert areas that may once have supported a rainforest understorey to drier eucalypt forests and woodlands.

Both species have lost some habitat: the sugar glider has lost lowland rainforest and riparian forest habitats, whereas the squirrel glider has lost the floodplain eucalypt vegetation. In the longer term, the species most vulnerable to the effects of ongoing deforestation in the study region is the squirrel glider since its distribution coincides with a part of the landscape that is currently experiencing ongoing deforestation. Thus, ecological dominance in this case has no benefit for long-term security in the face of habitat loss because it is offset by greater habitat specialisation.

In contrast, the habitat of the ecologically more flexible sugar glider is better protected since the vegetation of higher elevations is relatively less vulnerable to being cleared, both because it occurs in the mountain ranges where steeper slopes limit these areas' attractiveness for development, and because it is in these areas that conservation reserves are concentrated (Catterall et al. 1997). The dry eucalypt open-forest and woodland habitats required by squirrel gliders occur mainly at lower elevations and outside of the formal reserve system.

Queensland legislation has now been enacted which is designed to limit the clearance of vegetation, particularly vegetation communities that are poorly represented in the remaining vegetation cover (Vegetation Management Act 1999). However, the forest types in which squirrel gliders are abundant may still not be well protected. Under the Act, clearing can occur for activities such as dwelling construction, access, safety clearance and sustainable forestry activities without the need for a permit. Further deforestation may also be allowed in vegetation types that have more than $10 \%$ of their preEuropean extent remaining, under permits to clear. The protected vegetation communities comprise only a small proportion of remnant vegetation that makes up the squirrel glider's preferred habitat, and hence the ability of this legislation to adequately protect the habitat of species such as the squirrel glider remains to be tested.

Our conclusion is that the squirrel glider may experience a rapid decline within the urbanising south-east Queensland lowlands unless substantially more remnant vegetation is protected than currently seems likely.

\section{Acknowledgements}

We thank Scott Piper for help with the data summary and analyses. The Queensland Museum (Steve Van Dyck) and Orphaned Native Animal Rear and Release (Vicky Douglas) provided records of sugar and squirrel gliders collected in the study area. We thank Len Webb and
Bill MacDonald for discussions and advice concerning the interpretation of rainforest distribution maps. This study was supported by an Australian Postgraduate Research Award to CR, and additional financial support from the promoters of "The Great South East". 


\section{References}

Alexander, J. S. A. 1981. The Status of the Squirrel Glider, Petaurus norfolcensis (Marsupialia: Petauridae) in Victoria. Hons thesis. La Trobe Univerity, Vic.

Bennett, A. F., Lumsden, L. F., Alexander, J. S. A., Duncan, P. E., Johnson, P. G., Robertson, P. and Silveira, C. E. 1991. Habitat use by arboreal mammals along an environmental gradient in north-eastern Victoria. Wildlife Research 18: 125 - 146.

Braithwaite, L.W. 1983. Studies on the arboreal marsupial fauna of eucalypt forests being harvested for woodpulp at Eden, N.S.W. I. The species and distribution of animals. Australian Wildlife Research 10: 219-229.

Catterall, C. P. and Kingston, M. 1993. Remnant Bushland of South East Queensland in the 1990's: its Distribution, Loss, Ecological Consequences, and Future Prospects. Institute of Applied Environmental Research, Griffith University and Brisbane City Council, Brisbane.

Catterall, C. P., Storey, R. J. and Kingston, M. B. 1997. Reality versus rhetoric: a case study monitoring regional deforestation. Pp. 367-377 in Conservation Outside Nature Reserves, edited by P. Hale and D. Lamb. Centre for Conservation Biology, University of Queensland.

Chappell, M. A. 1978. Behavioural factors in the altitudinal zonation of chipmunks (Eutamias). Ecology 59: 565-579.

Connell, J. H. 1983. On the prevalence and relative importance of interspecific competition: evidence from field experiments. The American Naturalist 122: 661-696.

Davey, S. M. 1984. Habitat preferences of arboreal marsupials within a coastal forest in southern New South Wales. Pp. 509. 516 in Possums and Gliders, edited by A. P Smith and I. D. Hume. Australian Mammal Society, Sydney, NSW.

Fleay, D. 1947. The squirrel glider. Victorian Naturalist 70: 208-210.

Kingston, M., Catterall, C.P. and Kenyon, R. 1991. Remnant Bushland of South East Queensland (1989) Map Series. Institute of Applied Environmental Research, Griffith University, Qld.

Menkhorst, P. W. and Collier, M. 1987. Diet of the squirrel glider, Petaurus norfolcensis (Marsupialia: Petauridae), in Victoria. Australian Mammalogy 11: 109-116.

Menkhorst, P. W., Weavers, B. W. and Alexander, J. S. A. 1988. Distribution, habitat and conservation status of the squirrel glider Petaurus norfolcensis (Petauridae: Marsupialia) in Victoria. Australian Wildlife Research 15: 59-71.

Quin, D. G. 1993. Socioecology of the Squirrel Glider and the Sugar Glider. PhD thesis. University of New England.

Quin, D. G. 1995. Population ecology of the squirrel glider (Petaurus norfolcensis) and the sugar glider ( $P$. breviceps) (Marsupialia: Petauridae) at Limeburners Creek, on the central north coast of New South Wales. Wildlife Research 22: 471-505.

Rowston, C. 1998a. Nest and refuge tree usage by squirrel gliders, Petaurus norfolcensis, in south east Queensland. Wildlife Research 25: 157-164.

Rowston, C. 1998b. The Squirrel Glider: An Autecological Study in a Fragmented Landscape. PhD Thesis. Griffith University, Qld.

Rowston, C., Catterall, C. P. and Hurst, C. 2002. Habitat preferences of squirrel gliders, Petaurus norfolcensis, in the fragmented landscape of south east Queensland. Forest Ecology and Management.
Russell, R. 1995. Yellow-bellied glider. Pp. 226-227 in The Mammals of Australia, edited by R. Strahan. Reed books, NSW.

Smith, A. 1980. The Diet and Ecology of Leadbeater's Possum and the Sugar Glider. PhD thesis. Monash University.

Smith, A. P. 1982. Diet and feeding strategies of the marsupial sugar glider in temperate Australia. Journal of Animal Ecology 51: $149-166$.

Smith, A. 1993. Sugar glider possums to the rescue. Australian Horticulture 91: 16-17.

Smith, A. and Lee, A. 1984. The evolution of strategies for survival and reproduction in possums and gliders. Pp. 17-33 in Possums and Gliders, edited by A. P Smith and I. D. Hume. Australian Mammal Society, Sydney, NSW.

Smith, M.J. 1973. Petaurus breviceps. Mammalian species 30: 1-5.

Strahan, R. (ed.) 1995. The Mammals of Australia. Reed Books, Chatswood, N.S.W.

Suckling, G. C. 1984. Population ecology of the sugar glider, Petaurus breviceps, in a system of fragmented habitats. Australian Wildlife Research 11: 49-75.

Suckling, G. C. 1995. Squirrel Glider. Pp. 140 in The Mammals of Australia, edited by R. Strahan. Angus and Robertson Publishers, Sydney, NSW.

Traill, B.J. and Lill, A. 1997. Use of tree hollows by two sympatric gliding possums, the squirrel glider, Petraurus norfolcensis and the sugar glider, P. breviceps. Australian Mammalogy 20: 79-88.

Tyndale-Biscoe, C.H. and Calaby, J.H. 1975. Eucalypt forest as refuge for wildlife. Australian Forestry 38: 117-133.

Van Dyck, S. 1993. The taxonomy and distribution of Petaurus gracilis (Marsupialia: Petauridae), with notes on its ecology and conservation status. Memoirs of the Queensland Museum 33: $77-122$.

Webb, L. J. 1956. Environmental Studies in Australian Rainforests. $\mathrm{PhD}$ thesis. University of Queensland.

Winter, J. W. 1984. Conservation studies of tropical rainforest possums. Pp. 469-481 in Possums and Gliders, edited by A. P. Smith and I. D. Hume. Australian Mammal Society, Sydney, NSW.

Young, P. 1990. Vegetation of the Brisbane River. Pp. 83-89 in The Brisbane River. A Source Book for the Future, edited by P. Davie, E. Stock and D. Low Choy. Australian Littoral Society Inc. in association with the Queensland Museum, Brisbane.

Young, P. A. R. and Dillewaard, H. A. 1999. Southeast Queensland. Pp. 12/1-12/75 in The Conservation Status of Queensland's Bioregional Ecosystems, edited by P. Sattler and R. Williams. Environmental Protection Agency, Brisbane.

Young, P. A. R. and McDonald, W. J. F. 1987. The distribution, composition and status of the rainforests of southern Queensland. $\mathrm{Pp} 119-141$ in The Rainforest Legacy: Australian National Rainforests Study. Volume 1 - The Nature, Distribution and Status of Rainforest Types, edited by G. Werren and P. Kershaw. Australian Government Publishing Services, Canberra, ACT.

Ziv, Y., Ambramsky, Z., Kotler, B. P. and Subach, A. 1993. Interference competition and temporal and habitat partitioning in two gerbil species. Oikos 66: 237-246. 